Gut, 1968, 9, 125-128

\title{
Use of 2 deoxy-D-glucose to test for the completeness of surgical vagotomy
}

\author{
D. G. THOMAS AND H. L. DUTHIE \\ From the University Department of Surgery, Royal Infirmary, Sheffield
}

A synthetic analogue of glucose, 2-deoxy-D-glucose (2-DG), stimulates vagal hypothalamic centres by lowering intracellular glucose levels. This substance has been used to elicit the vagal phase of gastric secretion in the rat, dog, and man (Baume, Nicholls, Barnett, and Room, 1966; Hirschowitz and Sachs, 1965; Duke, Hirschowitz, and Sachs, 1965).

The acid response to 2-DG is equal to that produced by histamine infusion and greater than the response to insulin in the presence of intact vagal nerves (Duke et al., 1965). The stimulatory effect of 2-DG is reported to be abolished by the administration of atropine or by a complete surgical vagotomy (Hirschowitz and Sachs, 1965; Duke et al., 1965). It has been suggested that 2-DG may be superior to insulin for testing vagal mechanisms of stimulation of gastric secretion (Duke et al., 1965).

This paper presents a comparison between the use of insulin and 2-DG in the postoperative assessment of the completeness of surgical vagotomy.

\section{METHODS}

Thirty-seven patients with chronic duodenal ulceration were studied after the operation of vagotomy and pyloroplasty. This group was selected to contain a high prrcentage of patients with an incomplete vagotomy. Five patients had a selective vagotomy; the remainder had truncal vagotomy performed.

Each patient had both an insulin and a 2-DG test postoperatively. These tests were performed at least one week and not later than 20 months after operation.

All the tests were conducted in a similar manner. After a fast for 10 to 20 hours gastric contents were aspirated through either a Neoplex 16 FG nasogastric tube or through a gastrostomy tube. Continuous suction was employed at a pressure of 5 to $8 \mathrm{~cm} \mathrm{Hg}$, frequently freeing the lumen of the tube by puffing air down the tube by hand. After completely emptying the stomach, three basal 15-minute samples were collected followed by eight to 10 samples each of 15 minutes after the injection of insulin or 2-DG. The volume and titratable acidity of each 15 minute sample was measured.

The test substances were injected intravenously, either 20 units of soluble insulin over a period of five seconds or $2-\mathrm{DG}, 50 \mathrm{mg} / \mathrm{kg}$ body weight in a $25 \%$ solution, in 10 minutes.

All the results of the insulin tests were interpreted according to Hollander's criteria and are reported as concentrations of acid (m-equiv/l). A positive response was indicated by a rise of $20 \mathrm{~m}$-equiv/l free acid above the basal values unless the resting specimens contained no free acid, in which case a rise of $10 \mathrm{~m}$-equiv/l was significant (Hollander, 1948).

The results of the insulin tests were divided into negative and positive, indicating a complete or incomplete surgical vagotomy. The insulin-positive results were subdivided into two groups according to the timing of the acid response to insulin:-

1 'Early positive' indicates a positive insulin response in the first post-injection hour.

2 'Late positive' indicates a positive insulin response in the second hour after injection (Johnston, Thomas, Checketts, and Duthie, 1967).

\section{RESULTS}

An outline of the response to insulin and 2-DG is given in Table $\mathrm{I}$.

\section{TABLE I}

\begin{tabular}{lrl} 
Response to Insulin & Response to $2 D G$ \\
\hline Positive 22 Early + ve & 7 & All early + ve \\
Late + ve & 15 & All early + ve \\
Negative 15 & - ve 11 \\
& & Late + ve 4
\end{tabular}

NEGATIVE INSULIN TESTS Eleven of the 37 patients had negative insulin tests indicating a complete vagotomy. None of these patients showed a rise in acid concentration in response to 2-DG or insulin (Fig. 1).

EARLY POSITIVE INSULIN TESTS Seven of the 37 patients had an early positive insulin response. In these patients there was an earlier and more pronounced rise in acid concentration after 2-DG than after insulin (Fig. 2). 


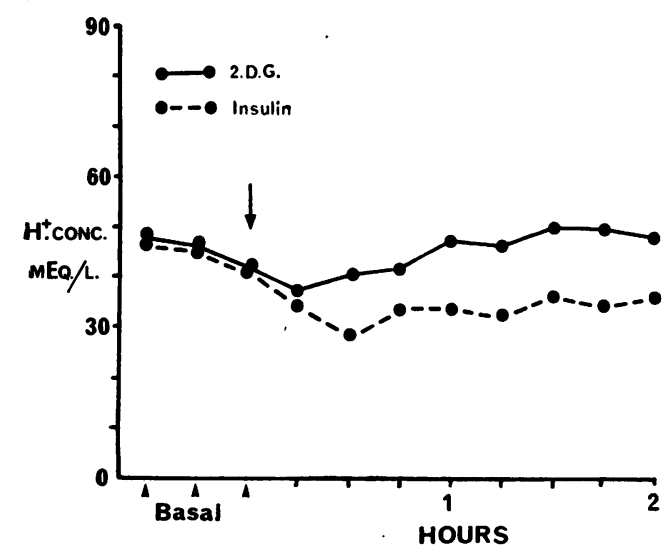

FIG. 1. Mean concentration of gastric acidity in 11 patients with negative insulin tests showing the lack of effect of intravenous injection $(\downarrow)$ of insulin 20 units and of 2 deoxy-D-glucose $50 \mathrm{mg} / \mathrm{kg}$.

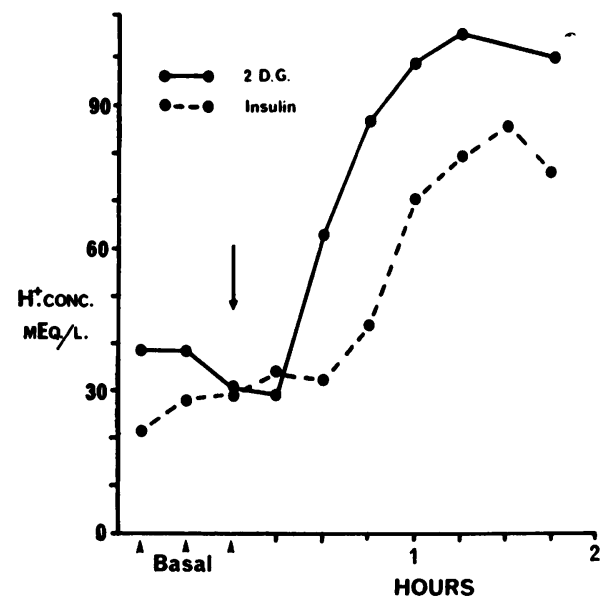

FIG. 2. Mean concentration of gastric acidity in seven patients with an early positive response to insulin showing the effect of intravenous injection $(\downarrow)$ of insulin 20 units and of 2 deoxy-D-glucose $50 \mathrm{mg} / \mathrm{kg}$. The response to $2-D G$ is earlier and more pronounced.

LATE POSITIVE INSULIN TESTS Fifteen of the 37 patients had a late positive insulin response. In this group, unlike insulin, 2-DG produced a prompt and more definite rise in acid concentration (Fig. 3).

It was not possible to subdivide the acid responses to 2-DG into early and late groups.

INCOMPATIBLE TESTS Four of the 37 patients had negative insulin tests and yet showed a definite rise in acid concentration in response to 2-DG (Fig. 4). One of the four patients has had a second insulin test, this again being negative. Three of the four patients have had only one insulin test.

SIDE EFFECTS Previous workers have noted no serious side effects following the administration of 2-DG, other than those of a mild hypoglycaemic-like state (Duke et al., 1965).

Thirty-four $(92 \%)$ of the patients in this series developed sweating, hunger, and thirst, but these symptoms were less severe and of shorter duration than the hypoglycaemic symptoms following injection of insulin in the same patients. However, three

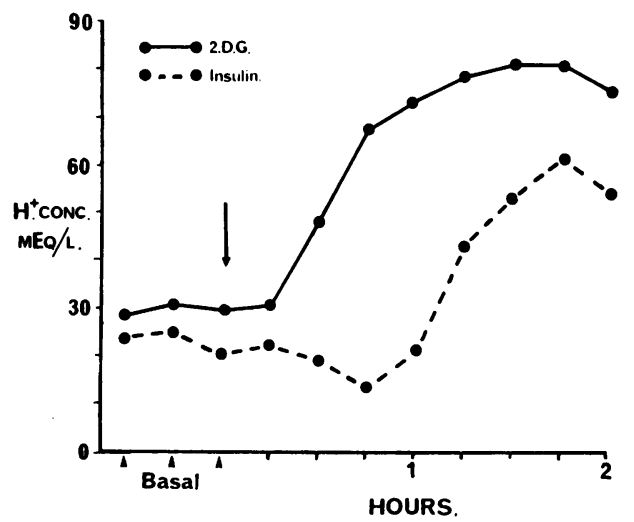

FIG. 3. Mean concentration of gastric acidity in 15 patients with a late response to insulin showing the effect of intravenous injection $(\downarrow)$ of insulin 20 units and of 2 deoxy-Dglucose $50 \mathrm{mg} / \mathrm{kg}$. The response to $2-D G$ is more prompt and more definite.

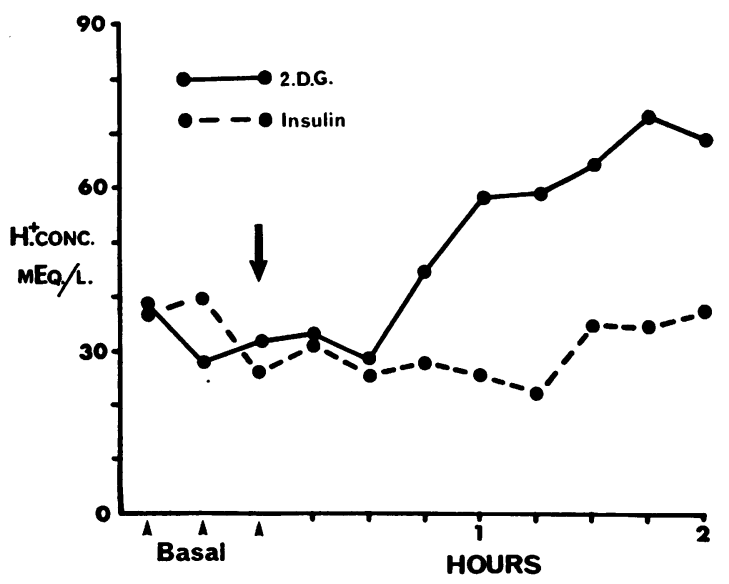

FIG. 4. Mean concentration of gastric acidity in four patients with incompatible tests in whom the intravenous injection of 2 deoxy-D-glucose $50 \mathrm{mg} / \mathrm{kg}$ produced a late response and the injection of insulin 20 units produced no response. 
patients developed an exaggerated hypoglycaemiclike state with alterations in body temperature down to $89^{\circ} \mathrm{F}$. One of these patients became semicomatose. This same patient also had severe hypoglycaemic symptoms after insulin. All the symptoms, with the exception of the alteration in body temperature, were rapidly reversed by the intravenous administration of $50 \%$ dextrose.

In some earlier preoperative 2-DG tests (unreported) two patients showed evidence of mild liver cell damage, one on the evidence of a liver biopsy. The second patient became jaundiced postoperatively with an increase in serum transaminase levels. As the 2-DG was given on the day of operation it was thought that the liver changes could have resulted from the combined effects of starvation, anaesthesia, and 2-DG. No further evidence of hepatotoxicity has been obtained in the postoperative series of tests.

\section{DISCUSSION}

In this comparative study the interpretation of the tests with 2 deoxy-D-glucose (2-DG) was always easy since the response when vagal fibres were intact was both prompt and definite. This allowed clear distinction from the negative group and so avoided some of the problems which have been found in the interpretation of the results of the insulin test (Bachrach, 1962; Bank, Marks, and Louw, 1967). This advantage of 2-DG over insulin must be regarded in the light of possible disadvantages. It was noted during the comparison that 2-DG, when eliciting a positive response, did so in the first 60 to 75 minutes after injection in contrast to insulin which might take up to two hours. No differentiation into early and late groups could be made with 2-DG, with the result that the prognostic value of this distinction would be lost. This value arises from the greater incidence of recurrent ulceration in patients with incomplete vagotomy who have an early positive response to insulin when compared with those who have a late response. A definite correlation has been found between the incidence of recurrent ulceration and the timing of the insulin response (Johnston et al., 1967). This more prompt response to 2-DG in itself may also prove useful. It should allow the test to be shortened from the two hours after injection when insulin is used to one hour if 2-DG is the best substance.

We have mentioned the ease of interpretation of the tests with 2-DG, and it should be added that in this laboratory little difficulty has been experienced in assessing the insulin test so long as care is taken to get an accurate basal level. However, in this study interpretation of the two tests jointly only proved a problem in the four anomalous tests. It would be ideal to have repeat insulin tests on all these patients but, unfortunately, we have only been able to do this on one patient. If it is assumed that the insulin results are valid, this small subgroup may prove most interesting, as they may be the small group who are liable to recurrent ulceration despite having a complete surgical vagotomy as indicated by a negative insulin test. Were this to be substantiated on followup of the patients, it would enhance the value of testing with 2-DG.

When any new substance is used for testing gastric secretion in man one of the main problems is the incidence of side effects. In this series the vast majority of patients had symptoms with 2-DG but, with the exception of three patients, these were not troublesome and were less obvious than the symptoms experienced with insulin. The three patients with severe side effects of hypothermia and some clouding of consciousness all responded promptly to the intravenous injection of $50 \%$ dextrose. It is rather difficult to explain the mechanism of this relief since the 2-DG is said to act by an intracellular glucopenia. However, it may be that the dextrose acted by mass action in reversing this deficiency. The potentially more harmful effect of liver damage was only seen in two patients, who were given 2-DG on the day of operation, and a multifactorial explanation seems likely for these transient changes.

As a result of this study it would seem that 2-DG has some advantages over insulin in the postoperative testing for completeness of surgical vagotomy. Further work should establish how valid these advantages are and elucidate the question of side effects.

\section{SUMMARY}

The use of 2 deoxy-D-glucose has been compared with that of insulin in the postoperative testing of 37 patients for completeness of surgical vagotomy.

2 Deoxy-D-glucose produced an earlier and more definite acid response than insulin in the presence of intact vagal fibres. It is suggested that 2 -DG has some advantages over insulin and further experience may show it to be superior.

\section{REFERENCES}

Bachrach, W. H (1962) Laboratory criteria for the completeness of vagotomy. Amer. J. dig. Dis., 7, 1071-1085.

Bank, S., Marks, I. N., and Louw, J. H. (1967). Histamine- and insulin-stimulated gastric acid secretion after selective and truncal vagotomy. Gut, 8, 36-41.

Baume, P. E., Nicholls, A., Barnett, R. A., and Room, R. A. (1966). Rat gastric acid secretion in response to graded subcutaneous doses of 2-deoxy-D-glucose. Amer. J. Physiol., 211, 626-628.

Duke, W. W., Hirschowitz, B. I., and Sachs, G. (1965). Vagal stimulation of gastric secretion in man by 2-deoxy-D-glucose. Lancet, 2 ,
$871-876$. 
Eisenberg, M. M., Emås, G. S., and Grossman, M. I. (1966). Comparison of the effect of 2-deoxy-D-glucose and insulin on gastric acid secretion in dogs. Surgery, 60, 111-117.

Hirschowitz, B. I., and O'Leary, D. K. (1964). Dose dependence of insulin-stimulated gastric secretion. Amer. J. dig. Dis., 9, 379-397.

, and Sachs, G. (1965). Vagal gastric secretory stimulation by 2-deoxy-D-glucose. Amer. J. Physiol. 209, 452-460.
Hollander, F. (1948). Laboratory procedures in the study of vagotomy (with particular reference to the insulin test). Gastroenterology, 11, 419-425.

Johnston, D., Thomas, D. G., Checketts, R. G., and Duthie, H. L. (1967). An assessment of postoperative testing for completeness of vagotomy. Brit. J. Surg., 54, 831-833. 